\title{
A systematic review of randomized controlled trials of mHealth interventions against non-communicable diseases in developing countries
}

\author{
Victor Stephani ${ }^{*} \mathbb{B}$, Daniel Opoku and Wilm Quentin
}

\begin{abstract}
Background: The reasons of deaths in developing countries are shifting from communicable diseases towards non-communicable diseases (NCDs). At the same time the number of health care interventions using mobile phones (mHealth interventions) is growing rapidly. We review studies assessing the health-related impacts of mHealth on NCDs in low- and middle-income countries (LAMICs).

Methods: A systematic literature search of three major databases was performed in order to identify randomized controlled trials (RCTs) of mHealth interventions. Identified studies were reviewed concerning key characteristics of the trial and the intervention; and the relationship between intervention characteristics and outcomes was qualitatively assessed.

Results: The search algorithms retrieved 994 titles. 8 RCTs were included in the review, including a total of 4375 participants. Trials took place mostly in urban areas, tested different interventions (ranging from health promotion over appointment reminders and medication adjustments to clinical decision support systems), and included patients with different diseases (diabetes, asthma, hypertension). Except for one study all showed rather positive effects of mHealth interventions on reported outcome measures.

Furthermore, our results suggest that particular types of mHealth interventions that were found to have positive effects on patients with communicable diseases and for improving maternal care are likely to be effective also for NCDs.

Conclusions: Despite rather positive results of included RCTs, a firm conclusion about the effectiveness of mHealth interventions against NCDs is not yet possible because of the limited number of studies, the heterogeneity of evaluated mHealth interventions and the wide variety of reported outcome measures. More research is needed to better understand the specific effects of different types of mHealth interventions on different types of patients with NCDs in LaMICs.
\end{abstract}

\section{Background}

As a result of increasing life-expectancy and growing welfare in low and middle income countries (LaMICs), there is a steady shift away from communicable to noncommunicable diseases (NCDs) [1-3]. NCDs pose a major threat to public health in LaMICs. In 2010, NCDs already accounted for half of Disability Adjusted Life Years (DALYs) lost and for $58 \%$ of all deaths in these

\footnotetext{
* Correspondence: Victor.Stephani@tu-berlin.de Department of Healthcare Management, Technische Universität Berlin, Berlin, Germany
}

(c) 2016 The Author(s). Open Access This article is distributed under the terms of the Creative Commons Attribution 4.0 International License (http://creativecommons.org/licenses/by/4.0/, which permits unrestricted use, distribution, and reproduction in any medium, provided you give appropriate credit to the original author(s) and the source, provide a link to the Creative Commons license, and indicate if changes were made. The Creative Commons Public Domain Dedication waiver (http://creativecommons.org/publicdomain/zero/1.0/) applies to the data made available in this article, unless otherwise stated.

countries [4]. It is predicted that this number will increase to $70 \%$ of all deaths in 2020 [5]. The economic cost of the NCDs burden for LaMICs are estimated to reach US $\$ 21$ trillion by 2030 [3].

The ability of LaMICs to provide treatment and care for the increasing number of patients with NCDs is limited by insufficient health care infrastructure, especially in rural areas [6]. At the same time there is a rapidly growing, hidden infrastructure: $90 \%$ of the world's population now lives within reach of a mobile phone signal [7] and the developing world has the fastestgrowing cellphone subscriber market in the world $[8,9]$ 
with a mobile-cellular subscription rate of almost $90 \%$ in 2013 [10].

The number of health care interventions using mobile phones (short mHealth interventions) is growing rapidly [11]. In particular in LaMICs, mHealth is perceived to have great potential for improving health care provision for both communicable and non-communicable diseases [12]. Most of the available literature on mHealth interventions is focused on communicable diseases (such as HIV and Malaria) or on maternal care [13]. However, the number of studies focusing on mHealth for patients with NCDs has considerably increased over the last few years. In fact, two thirds of all articles on the topic have been published between 2012 and 2015 (based on a Web of Science search with the keywords TS $=($ mHealth OR "mobile Health" or tele*) AND TS = ("developing") AND TS $=(\mathrm{NCD}$ OR "non-communicable diseases"). Yet, evaluations of mheatlh interventions often do not follow rigorous scientific standards of randomized controlled trials (RCTs), and consequently, they carry a relatively high risk of bias [14].

Two reviews are available that have included studies analyzing certain aspects of mHealth interventions for NCDs in LaMICs: Beratarrechea et al. [15] evaluated text and automated voice interventions for chronic diseases in the developing world and Bloomfield et al. [16] performed a review of mHealth interventions against NCDs focusing only on Sub-Saharan African countries. However, as Beratarrechea et al. [15] did not focus specifically on NCDs and because Bloomfield et al. [16] focused exclusively on Sub-Saharan Africa, a comprehensive overview of the effectiveness of mHealth interventions for improved treatment and care of patients with NCDs living in LaMICs remains unavailable.

The aim of this study was 1) to systematically review the available evidence generated by randomized controlled trials (RCTs) of mHealth interventions for people with NCDs living in LaMICs, and 2) to assess the relationship between intervention characteristics and reported healthrelated outcomes. We focused on RCTs since they remain the gold standard for evidence of effectiveness of health interventions [17].

\section{Method}

\section{Inclusion criteria}

Studies were included for this review if they met the following inclusion criteria:

- The study reported results of an RCT, as defined by JN Matthews [18]

- The trial took place in at least one country that was classified as an LaMIC as defined by the World Bank classification of country income groups [19]
- The intervention involved the use of mHealth as defined by the Global Observatory for eHealth [11]

- Trial participants were patients suffering from NCDs as defined by the WHO [20]

- The study was published in English or German

- The study was published before August 2015 (no limit concerning the start date)

\section{Literature search method}

An initial systematic literature search was performed between December 2013 and February 2014 in MEDLINE (PubMed), CENTRAL and Business Source Complete. An update of the search was performed in August 2015.

After piloting appropriate search words, the terms were constructed around (1) "mHealth", (2) "Low and Middle Income Countries" and (3) "Non Communicable Disease". Search terms for the operationalization of NCDs were derived from WHO's Global Burden of Disease Report. In addition to the medical terms specified in the Global Burden of Disease Report (e.g., myocardial infarction or dermatological cancer), we added more common terms such as heart or skin (for including interventions against skin cancer) to the search algorithm.

The search conducted in CENTRAL is shown in the Additional file 1: Table S1. It was carried out using the free text search with Boolean operators and MeSH descriptors using the terms Telemedicine [MeSH] AND Developing Countries [MeSH] (with no filter for diseases and the enabled option of exploding all trees). The same search-approach was applied using MEDLINE. Due to a low number of results in the database Business Source Complete it was feasible to exclude the field of terms for NCDs and to include solely the location and intervention of interest.

In addition, reference lists of included studies and identified existing reviews were screened for relevant titles.

After removal of duplicates, the resulting list of titles (Medline 730, CENTRAL 116, Business Source Complete 125) was screened and studies whose titles/ abstracts clearly indicated that they were not concerned with mHealth intervention trials for NCDs in LaMICs (e.g., if titles indicated that they focused on developed countries or HIV) were excluded from further consideration.

Full-text articles of 114 studies were retrieved and assessed, resulting in 8 articles included for this review. The screening process was conducted independently by two reviewers (VS and DO). Disagreements were discussed between authors and resolved by consensus.

\section{Data collection and analysis}

For each included study, information was collected on key characteristics of the RCTs concerning: 
1) the study location (country, urban/rural);

2) the population (disease, inclusion and exclusion criteria for trial participants);

3) the intervention characteristics, including information on the type of mHealth intervention (e.g., text message, phone call), the data transmitted (e.g., appointment reminders, advice and medication reminders), interactivity of the intervention (i.e., whether it was possible for patients or providers to respond to information received), and personalization (i.e., whether timing or content of information were specific for the patient);

4) the comparator (control) group intervention (e.g., booklet with information on asthma instead of text message with information); and

5) outcomes reported by the studies, including clinical outcomes, compliance, quality of life, costs and other outcomes.

In order to assess the relationship between intervention characteristics and outcomes, studies were categorized into one of four types of mHealth interventions as suggested by Howitt et al. [21] (with slight modifications). We distinguished between interventions for 1) health promotion \& awareness, 2) remote monitoring \& care support, 3) disease surveillance \& outbreak detection, and 4) decision support system.

Meta-analytic techniques were not employed because differences between studies concerning the type of intervention, the included study participants (different diseases), and the reported outcome measures (clinical outcomes, compliance, etc.) made a meaningful analysis of pooled data impossible.

\section{Risk of bias}

Risk of bias was assessed qualitatively concerning selection bias (sequence generation and allocation sequence concealment), performance bias (blinding of participants and personnel), detection bias (blinding of outcome assessment), extent of loss to follow-up, reporting bias (selective outcome reporting), and other bias (e.g., imbalance in baseline characteristics). We used the Cochrane Collaboration's tool for assessing risk of bias and information on assessment were derived from the text [22]. The full risk assessment of the included studies is available in the Additional file 2.

\section{Results}

\section{Literature search results}

Figure 1 illustrates the literature search and selection process, and presents reasons for exclusion of studies. We identified a total of 969 studies in the three databases and 23 studies were retrieved from references of other studies. Full texts of 114 studies were screened of which 106 were excluded, mostly because they did not deal with mHealth $(n=43)$, did not report results of an RCT $(n=25)$, did not take part in LaMICs $(n=13)$ or because of other reasons $(n=25)$. The final analysis included 8 studies, which met all inclusion criteria.

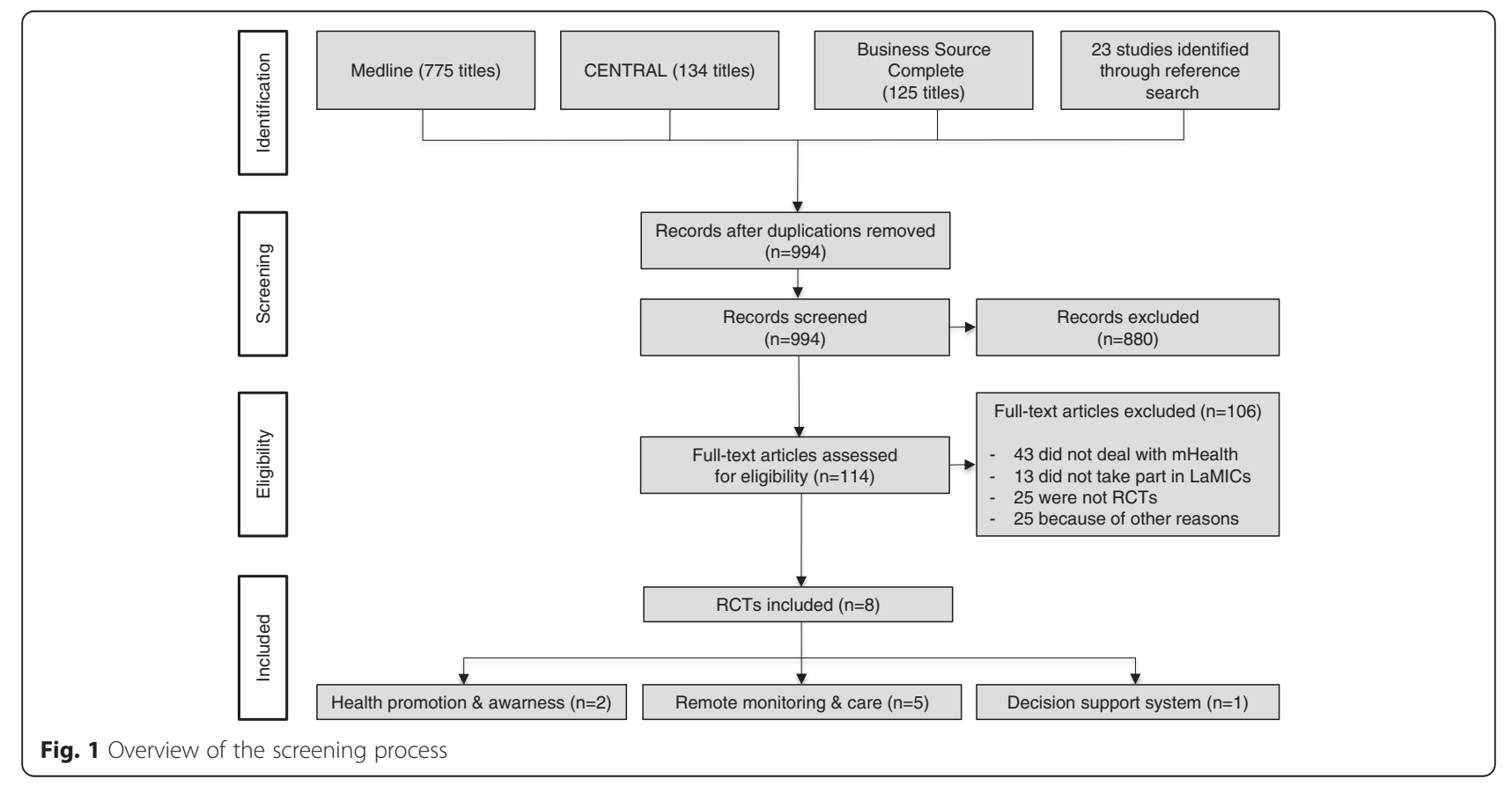




\section{Characteristics of included studies Trial characteristics}

Table 1 summarizes the main characteristics of the eight included trials. Five studies were conducted in lower middle income countries (LMICs), three in upper middle income countries (UMICs). Two studies [23, 24] reported results of trials, which included patients in both a LMIC and a UMIC (Mexico and Honduras, and India and China, respectively). The participating patients came mostly from urban areas and were recruited mainly from primary care centers or urban hospitals. Three studies dealt with diabetes [25-27], two with asthma patients $[28,29]$, two with patients suffering from cardiovascular diseases, [23, 24] and one with patients having different NCDs [30], including hypertension, asthma and diabetes.

A total of 4375 participants were included in all eight studies, of whom 2095 received a mHealth intervention, 314 received an alternative landline-telephone based intervention, and 1966 were included in the control group. Trial size varied from 16 participants [29] to 2086 participants [24]. The mean age in the intervention group was 57.2 years and in the control group 57.8 years. Studies reported a wide range of outcomes, which were classified for the purposes of our review into disease specific clinical outcomes, compliance and others.

\section{Intervention characteristics}

Table 2 provides an overview about the main characteristics of the mHealth interventions that were evaluated in the eight RCTs. Two interventions informed patients with diabetes about the management of the disease and gave general advice on a healthy lifestyle (category health promotion \& awareness): One informed the participants through an internet webpage and frequently sent text messages [25], while the other sent a text message once in three days to the study participants [26]. Both interventions were not personalized to the participants and not interactive.

The most basic intervention in the category of remote monitoring \& care support was an appointmentreminder system, where text messages were sent 24-48 $\mathrm{h}$ before the patients' scheduled appointments [30].

Four interventions required the patients to record key parameters of their disease, e.g., the Peak Expiratory Flow Rate (PEFR) for patients with Asthma [28, 29], the blood glucose level for patients with Diabetes [27] or the blood pressure for patients with hypertension [23]. They did so by using additional devices (home blood pressure monitor, glucometer, peak expiratory flow meter) and the patients were then asked to send this data either via a text message to a physician [29], to type their records into an interactive phone software [28] or they were called by a specialist and transmitted the information via a phone-call $[23,27]$. In all the four studies, patients received personalized disease-management advice.

Only one intervention fell into the category of clinical decision support systems [24]. Community health workers (CHWs) treating patients with cardiovascular diseases in rural areas received a smartphone with an application consisting of prompts regarding the patients' clinical values, adherence to treatment and other parameters. The application was tailored to the local customs.

\section{Results of the RCTs}

Table 3 provides an overview of all relevant outcomes reported by the eight included studies, illustrating significance of differences in outcomes between the intervention and control groups. The eight studies reported results for a total of 15 different measures of clinical outcome 9 measures of compliance, 2 measures of quality of life (QoL) and 13 other outcome measures.

The two health promotion $\mathcal{E}$ awareness interventions targeted diabetic patients but none of the reported outcome measures was available from both studies. In the study by Balsa and Gandelman [25], where diabetic patients received a text message that intended to motivate their use of a website, neither clinical outcomes nor other outcomes were improved. In the study by Shetty et al. [26], where patients received a text message with advice on nutrition, physical activity and drug intake, several clinical outcome measures showed significant improvements, although compliance measures did not improve significantly.

Out of the five studies evaluating tools for remote monitoring and care support, one study evaluated an interactive telephone-intervention for patients with diabetes [27]. Patients were advised to self-monitor their Blood Glucose level and received therapeutic advice over the phone twice a month. The study found that clinical and compliance outcomes improved significantly more strongly in the intervention group than in the control group.

Two studies evaluated interactive mHealth interventions for patients with asthma [28, 29], where patients transmitted information about their pulmonary function (as assessed by the peak expiratory flow rate, PEFR) to a physician and received personalized therapeutic advice (e.g., medication adjustments). Both studies found that individuals showed improved pulmonary function tests (FEV1\% predicted and PEFR), although this finding was not significant in the study by Ostojic et al. [29], which included only a total of 16 participants. Liu et al. [28] also found significant improvements of quality of life, while Ostojic et al. [29] found significant improvements of PEFR variability and of some self-reported clinical outcome measures (e.g., coughing and night symptoms) although not of others, and no effect on compliance. 
Table 1 Characteristics of the interventions

\begin{tabular}{|c|c|c|c|c|c|c|}
\hline \multirow[b]{2}{*}{ Study name } & \multicolumn{2}{|l|}{ Intervention } & \multirow[b]{2}{*}{ Control group } & \multirow[b]{2}{*}{ Timing } & \multirow[b]{2}{*}{ Interactivity } & \multirow[b]{2}{*}{ Personalization } \\
\hline & Used channel & Received information & & & & \\
\hline $\begin{array}{l}\text { Balsa and } \\
\text { Gandelman [25] }\end{array}$ & $\begin{array}{l}\text { Internet platform \& text } \\
\text { messages }\end{array}$ & $\begin{array}{l}\text { New topics about type } 2 \text { Diabetes and } \\
\text { healthy lifestyle }\end{array}$ & Brief educational brochure & Not reported & No & No \\
\hline Shetty et al. [26] & Text messages & $\begin{array}{l}\text { Medical nutrition therapy, physical activity } \\
\text { and drug intake reminders }\end{array}$ & $\begin{array}{l}\text { Oral advises on diet modification } \\
\text { and physical activity }\end{array}$ & Once in three days & No & No \\
\hline Liew et al. [30] & Text messages & Appointment reminder & No reminder & $\begin{array}{l}\text { Once; } 24-48 \mathrm{~h} \text { before the } \\
\text { scheduled appointment }\end{array}$ & No & Yes \\
\hline Liu et al. [28] & $\begin{array}{l}\text { Interactive software on } \\
\text { cellphone }\end{array}$ & Adjustments of therapy & $\begin{array}{l}\text { Booklet for written asthma diary and } \\
\text { action plan }\end{array}$ & $\begin{array}{l}\text { Immediately after the data has } \\
\text { been uploaded }\end{array}$ & Yes & Yes \\
\hline Ostojic et al. [29] & Text messages & Adjustments of therapy & No weekly therapeutic advise & Weekly & Yes & Yes \\
\hline Piette et al. [23] & $\begin{array}{l}\text { Mobile blood pressure } \\
\text { monitor \& phone calls }\end{array}$ & Advises and medication reminder & No weekly therapeutic advise & Weekly & Yes & Yes \\
\hline Shahid et al. [27] & Glucometer \& Phone calls & Adjustments of therapy & $\begin{array}{l}\text { Self monitoring with Glucometer } \\
\text { and regular follow up after } 4 \text { months }\end{array}$ & Every 15 days & Yes & Yes \\
\hline Tian et al. [24] & Smartphone application & $\begin{array}{l}\text { Advises on medication prescription and } \\
\text { lifestyle changes }\end{array}$ & $\begin{array}{l}\text { Usual cardiovascular management } \\
\text { programs }\end{array}$ & Monthly & No & Yes \\
\hline
\end{tabular}


Table 2 Study design characteristics of included RCTs

\begin{tabular}{|c|c|c|c|c|c|c|c|c|c|}
\hline Study & Location & $\begin{array}{l}\text { Income } \\
\text { group }\end{array}$ & Conditions & Place of recruitment & Inclusion criteria & Sample size & $\begin{array}{l}\text { Mean Age } \\
\text { (Intervention; } \\
\text { control) }\end{array}$ & $\begin{array}{l}\text { Planned } \\
\text { Follow-up }\end{array}$ & $\begin{array}{l}\text { Measured } \\
\text { outcomes }\end{array}$ \\
\hline $\begin{array}{l}\text { Balsa and } \\
\text { Gandel-man [25] }\end{array}$ & $\begin{array}{l}\text { Uruguay } \\
\text { (urban) }\end{array}$ & UMIC & Type 2 Diabetes & $\begin{array}{l}\text { Waiting rooms of internists } \\
\text { treating diabetic patients } \\
\text { at three HMOs in Montevideo }\end{array}$ & $\begin{array}{l}\text { Adult patients with Diabetes } \\
\text { 2; Access to Internet (at least } \\
\text { once a week) }\end{array}$ & $\begin{array}{l}195 \text { (intervention) } \\
193 \text { (control) }\end{array}$ & $n / d$ & 6 months & $\begin{array}{l}\text { Clinical, } \\
\text { Others }\end{array}$ \\
\hline Shetty et al. [26] & India (urban) & LMIC & Diabetes & $\begin{array}{l}\text { Patients at a diabetes centre } \\
\text { in Chennai }\end{array}$ & $\begin{array}{l}\text { Type } 2 \text { Diabetes with a } \\
\text { minimum duration of } 5 \text { years; } \\
\text { Minimum of high school } \\
\text { Education; HbA1c value ranging } \\
\text { between } 7 \% \text { to } 10 \%\end{array}$ & $\begin{array}{l}110 \text { (intervention) } \\
105 \text { (control) }\end{array}$ & $50.1 ; 50.5$ & 1 year & $\begin{array}{l}\text { Clinical, } \\
\text { Compliance }\end{array}$ \\
\hline Liew et al. [30] & $\begin{array}{l}\text { Malaysia } \\
\text { (urban) }\end{array}$ & UMIC & $\begin{array}{l}\text { Different chronic } \\
\text { diseases } \\
\text { (mainly NCDs) }\end{array}$ & $\begin{array}{l}\text { Two primary care clinics in } \\
\text { Kuala Lumpur }\end{array}$ & $\begin{array}{l}\text { Registered with the clinics for at } \\
\text { least } 6 \text { months; return appointment } \\
\text { between } 1 \text { and } 6 \text { months; } \\
\text { ownership of a mobile phone }\end{array}$ & $\begin{array}{l}314 \text { (telephone) } \\
398 \text { (text } \\
\text { mesages) } \\
309 \text { (control) }\end{array}$ & $\begin{array}{l}57.7 ; 58.1 ; \\
60.7\end{array}$ & $\begin{array}{l}\text { At least } \\
6 \text { months }\end{array}$ & Compliance \\
\hline Liu et al. [28] & Taiwan (urban) & UMIC & Asthma & $\begin{array}{l}\text { Outpatient clinics of Chang } \\
\text { Gung Memorial Hospital, } \\
\text { Linkou, northern Taiwan }\end{array}$ & Moderate to severe Asthma & $\begin{array}{l}43 \text { (intervention) } \\
46 \text { (control) }\end{array}$ & $\begin{array}{l}54 ; \\
50\end{array}$ & 6 months & $\begin{array}{l}\text { Clinical, } \\
\text { Compliance, } \\
\text { QoL }\end{array}$ \\
\hline $\begin{array}{l}\text { Ostojic et al. } \\
\text { [29] }\end{array}$ & Croatia (urban) & UMIC & Asthma & $\begin{array}{l}\text { General Hospital "SvetiDuh", } \\
\text { Zagreb }\end{array}$ & $\begin{array}{l}\text { Moderate Asthma for at least } 6 \\
\text { months; consistent access to a } \\
\text { cellphone, able to use text messages }\end{array}$ & $\begin{array}{l}8 \text { (intervention) } \\
8 \text { (control) }\end{array}$ & $24.5 ; 24.8$ & 16 weeks & $\begin{array}{l}\text { Clinical, } \\
\text { Compliance, } \\
\text { Costs }\end{array}$ \\
\hline Piette et al. [23] & $\begin{array}{l}\text { Honduras } \\
\text { (rural), } \\
\text { Mexico (urban) }\end{array}$ & UMIC, LMIC & Hypertension & $\begin{array}{l}\text { Four private and two public } \\
\text { clinics in Cortes, Honduras } \\
\text { and one primary care center } \\
\text { in Real de Monte }\end{array}$ & $\begin{array}{l}\mathrm{SBP}>=130 \mathrm{~mm} \mathrm{Hg} \text { if diabetic and } \\
\mathrm{SBP}>=140 \mathrm{~mm} \mathrm{Hg} \text { if non-diabetic; } \\
\text { between } 18 \text { and } 80 \text { years; access } \\
\text { to a cellphone and able to use it }\end{array}$ & $\begin{array}{l}89 \text { (intervention) } \\
92 \text { (control) }\end{array}$ & $58.0 ; 57.1$ & 6 weeks & $\begin{array}{l}\text { Clinical, } \\
\text { Others }\end{array}$ \\
\hline $\begin{array}{l}\text { Shahid et al. } \\
\text { [27] }\end{array}$ & Pakistan (rural) & LMIC & Diabetes & $\begin{array}{l}\text { Department of Endocrinology, } \\
\text { Liaquat National Hospital }\end{array}$ & $\begin{array}{l}\text { Patients between } 18-70 \text { years, } \\
\text { residing in rural areas of Pakistan, } \\
\mathrm{HbA} 1 \mathrm{C} \geq 8.0 \% \text { and having personal } \\
\text { functional mobile phone }\end{array}$ & $\begin{array}{l}220 \text { (intervention) } \\
220 \text { (control) }\end{array}$ & $48.95 ; 49.21$ & 6 months & $\begin{array}{l}\text { Clinical, } \\
\text { Compliance }\end{array}$ \\
\hline Tian et al. [24] & $\begin{array}{l}\text { China (rural), } \\
\text { India (rural) }\end{array}$ & UMIC, LMIC & $\begin{array}{l}\text { Cardiovascular } \\
\text { Diseases }\end{array}$ & $\begin{array}{l}\text { CHWs at } 27 \text { villages from } 15 \\
\text { townships in China and } 20 \\
\text { villages in Haryana State, India }\end{array}$ & $\begin{array}{l}\text { High cardiovascular risk individuals: } \\
\text { above } 40 \text { years and a self-reported } \\
\text { history of coronary disease }\end{array}$ & $\begin{array}{l}1095 \\
\text { (intervention); } \\
991 \text { (control) }\end{array}$ & $59.7 ; 60.4$ & One year & $\begin{array}{l}\text { Clinical, } \\
\text { Compliance }\end{array}$ \\
\hline
\end{tabular}


Table 3 Overview of intervention-group outcomes compared to control-group outcomes

\begin{tabular}{|c|c|c|c|c|c|c|c|c|}
\hline Study & $\begin{array}{l}\text { Balsa and } \\
\text { Gandelman [25] }\end{array}$ & $\begin{array}{l}\text { Shetty et al. } \\
{[26]}\end{array}$ & $\begin{array}{l}\text { Shahid et al. } \\
{[27]}\end{array}$ & $\begin{array}{l}\text { Ostojic et al. } \\
\text { [29] }\end{array}$ & $\begin{array}{l}\text { Liu et al. } \\
\text { [28] }\end{array}$ & $\begin{array}{l}\text { Piette et al. } \\
\text { [23] }\end{array}$ & $\begin{array}{l}\text { Liew et al. } \\
{[30]}\end{array}$ & Tian et al. [24] \\
\hline Intervention & \multicolumn{2}{|c|}{$\begin{array}{l}\text { Health promotion \& } \\
\text { awareness }\end{array}$} & \multicolumn{5}{|c|}{ Remote monitoring \& care support } & $\begin{array}{l}\text { Decision support } \\
\text { system }\end{array}$ \\
\hline Personalization & \multicolumn{2}{|l|}{ No } & \multicolumn{5}{|l|}{ Yes } & \\
\hline Interactivity & \multicolumn{2}{|l|}{ No } & \multicolumn{4}{|l|}{ Yes } & \multicolumn{2}{|l|}{ No } \\
\hline Disease & Diabetes & & & Asthma & & $\begin{array}{l}\text { Hyper- } \\
\text { tension }\end{array}$ & $\begin{array}{l}\text { Various } \\
\text { NCDs }\end{array}$ & CVDs \\
\hline \multicolumn{9}{|l|}{ Clinical outcomes } \\
\hline $\mathrm{SBP}^{\mathrm{a}}(\mathrm{mm} \mathrm{Hg})$, Mean & $+/-$ & & ++ & & & $+/++^{\mathrm{b}}$ & & ++ \\
\hline Fasting blood glucose level & $+/-$ & & & & & & & \\
\hline $\mathrm{BMI}^{\mathrm{c}}, \mathrm{kg} / \mathrm{m}^{2}$ & & $+/^{d}$ & $+/-^{e}$ & & & & & \\
\hline $\mathrm{PPG}^{\mathrm{f}}<180 \mathrm{mg}$ & & ++ & & & & & & \\
\hline $\mathrm{HbA1} c^{9}$ & & $++^{h}$ & $++^{i}$ & & & & & \\
\hline $\mathrm{TC}^{\mathrm{j}}<150 \mathrm{mg} / \mathrm{dl}$ & & ++ & & & & & & \\
\hline $\mathrm{HDL}-\mathrm{C}^{\mathrm{k}}>40 \mathrm{mg} / \mathrm{dl}$ & & $+/-$ & & & & & & \\
\hline LDL-C $<100 \mathrm{mg}$ & & ++ & ++ & & & & & \\
\hline FEV $1 \%{ }^{\mathrm{m}}$, predicted & & & & + & ++ & & & \\
\hline $\mathrm{PEFR}^{\mathrm{n}}, \mathrm{L} / \mathrm{min}$ & & & & + & ++ & & & \\
\hline PEFRvariability & & & & ++ & & & & \\
\hline Coughing & & & & ++ & & & & \\
\hline Night symptoms & & & & ++ & & & & \\
\hline Wheezing & & & & $+/-$ & & & & \\
\hline Limitation of activities & & & & $+/-$ & & & & \\
\hline \multicolumn{9}{|l|}{ Compliance outcomes } \\
\hline Attendance & & + & & & & & ++ & \\
\hline $\mathrm{ICS}^{\circ}$ dosage & & & & $+/-$ & + & & & \\
\hline Systemic steroids & & & & $+/-$ & + & & & \\
\hline Antileukotrienes & & & & $+/-$ & $+/-$ & & & \\
\hline \multicolumn{9}{|l|}{ Long-acting beta2-agonist } \\
\hline $\begin{array}{l}\text { Anti-hypertensive medication } \\
\text { use }\end{array}$ & & & & & & & & ++ \\
\hline Aspirin & & & & & & & & ++ \\
\hline Adherence to diet prescription & & $+/-$ & ++ & & & & & \\
\hline Adherence to physical activity & & + & ++ & & & & & \\
\hline \multicolumn{9}{|l|}{ Quality of life related outcomes } \\
\hline Physical component & & & & & ++ & & & \\
\hline Mental component & & & & & ++ & & & \\
\hline \multicolumn{9}{|l|}{ Cost } \\
\hline Monetary & & & & - & & & & \\
\hline Timely & & & & - & & & & \\
\hline \multicolumn{9}{|l|}{ Other outcomes } \\
\hline Knowledge & $+/-$ & & & & & & & \\
\hline Perception of health quality & $+/-$ & & & & & & & \\
\hline Health-related behaviors & $+/-$ & & & & & & & \\
\hline Physician-Patient relationship & $+/-$ & & & & & & & \\
\hline
\end{tabular}


Table 3 Overview of intervention-group outcomes compared to control-group outcomes (Continued)

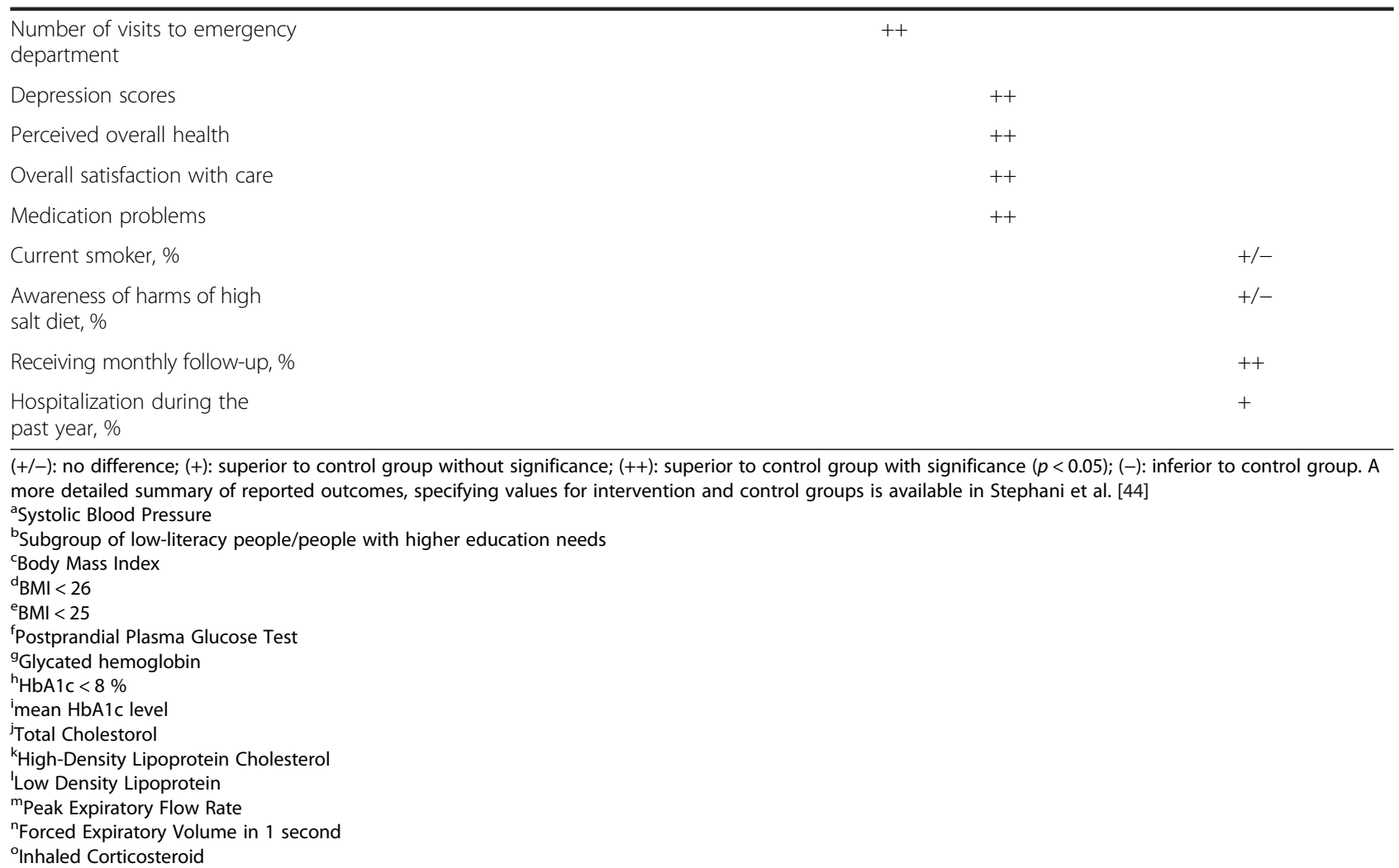

Piette et al. [23] found that their intervention providing personalized advice to hypertensive patients on the basis of their self-recorded blood pressure lowered systolic blood pressure in the intervention group, although this finding was significant only in a subgroup of 117 out of 181 participants with low literacy or high hypertension information needs.

Liew et al. [30] found that text messages and telephone appointment reminders lowered non-attendance of patients significantly when compared to controls.

The only study of a decision support system by Tian et al. [24] found that medication compliance of patients treated by CHWs, who were supported by smartphones, increased significantly, and they had significantly lower blood pressure when compared with controls.

The impact of mHealth on costs in terms of time and money for physicians and patients was observed by only one trial [29]. It was estimated that the intervention would lead to additional monetary costs per patient of $€ 0.67$ per week for text messages sent to physicians, and that physicians spent $2 \mathrm{~min}$ per patient per week at a cost of 1 Euro per patient.

\section{Discussion}

This is the first review focusing specifically on RCTs of mHealth interventions against NCDs in LaMICs. Despite much enthusiasm about the 'great potential' of mHealth for addressing NCD needs in LaMICs and despite a growing body of literature on the topic, we found only eight studies that reported results of RCTs performed in LaMICs. Except for one study [25], these showed generally positive effects of mHealth interventions on reported outcome measures. However, because trials tested different interventions (ranging from health promotion over appointment reminders and medication adjustments to clinical decision support systems), and included patients with different diseases (diabetes, asthma, hypertension), and - partially as a result of this - reported very different outcome measures, it is impossible to generalize these findings.

Nevertheless, our review provides a first glimpse of the slowly emerging evidence base on the effectiveness of mHealth interventions for NCDs and has important implications for policy-makers and researchers. First, it is remarkable that the evaluated $\mathrm{mHealth}$ interventions generally showed positive effects on reported outcome measures, including clinical outcomes, compliance, and quality of life. This finding is in line with findings from a much broader literature on communicable disease and maternal care, where many different kinds of mHealth interventions have been found to improve clinical outcomes and compliance of patients - although results have been shown to vary depending on the specific type of intervention [31-33]. 
Second, our results suggest that particular types of mHealth interventions that were found to have positive effects on patients with communicable diseases and for improving maternal care are likely to be effective also for NCDs. For example, text message appointment reminders have been found to lead to higher pre-natal visit rates of pregnant women [34-36], and two studies included in our review show that they are also effective at increasing attendance rates of patients with NCDs [26, 30]. Similarly, drug intake reminders have been found to improve treatment adherence of people with AIDS and Malaria [37-39], and one study in our review showed that drug intake reminders (combined with other information on medical nutrition and physical activity) improve clinical outcomes of patients with Diabetes [26].

Third, our results show that there is very limited evidence on the effects of mhealth in low income countries as all included studies reported results of trials conducted in middle income countries. Furthermore, when considering the 4 broad categories of mHealth interventions that we defined at the beginning, i.e., interventions of 1) health promotion \& awareness, 2) remote monitoring \& care support, 3) disease surveillance \& outbreak detection, and 4) decision support system, it is evident that available RCTs have focused mostly on mHealth interventions falling into category 2. Also Bloomfield et al. [16] concluded that there is very limited evidence concerning a wide range of health systems challenges, which could potentially be addressed by the implementation of mHealth interventions. In our review, several studies evaluating clinical decision support systems were identified during full-text screening [40-43] but they had to be excluded because they were no RCTs. Information on cost-effectiveness of mHealth interventions is largely unavailable and only one study included in our review considered the effect of mHealth on costs of care [29].

An important limitation of our review is that we excluded all studies that did not report results of RCTs. Observational studies and non-randomized trials may provide important bits of information that are useful for understanding the effectiveness of mHealth. Nevertheless, we opted for excluding these studies as nonrandomized trial designs carry a greater risk of being flawed as a result of multiple biases [22]. Another limitation of the review process could have been the restriction to the two languages German and English. Furthermore, given the limited number of studies, it was not possible to compare results of different studies. Effects of mHealth are likely to differ depending on the specific type of intervention, the specific disease, and the specific context. Consequently, it is impossible to draw firm conclusions on the effectiveness of mHealth interventions in general, e.g., by carrying out pooled analyses of outcome data. Finally, the specific effects of different kinds of mHealth interventions on different kinds of patients with NCDs living in LaMIC could not be investigated. For example, it is likely that the effectiveness of interventions depends on whether patients can interact with health professionals and whether information is personalized to the patients. Although our review includes studies with both interactive and non-interactive interventions as well as studies with both personalized and non-personalized information, the specific effects of these different interventions could not be compared because they were provided to different patients (in difference settings) and reported different outcome measures.

\section{Conclusion}

Our review shows that there are only eight studies reporting results of RCTs of mHealth interventions for patients with NCDs in LaMICs. These have generally found positive results. However, a more detailed analysis of the specific effects of different types of mHealth interventions on different types of patients and a firm conclusion about the effectiveness of mHealth against NCDs is impossible because of the small number of studies and the heterogeneity of reported outcome measures.

Nevertheless, our results indicate that some findings of the positive effects of mHealth interventions for patients with communicable diseases and for maternal care can be replicated by mhealth interventions for patients with NCDs. However, we can only repeat the conclusions of previous reviews $[15,16]$ that more research is needed to fill the many gaps in knowledge about mHealth interventions for NCDs in LaMICs.

\section{Additional files}

Additional file 1: Table S1. Search method conducted with the CENTRAL-database (DOC $30 \mathrm{~kb}$ )

Additional file 2: Table S2. Bias of the included studies (DOC $34 \mathrm{~kb}$ )

\section{Abbreviations}

CHWs, community health workers; DALYs, Disability Adjusted Life Years; FEV1\%, Forced Expiratory Volume in 1 second; LaMICs, low and middle income countries; LMICs, lower middle income countries; mHealth, mobile health; NCDs, non-communicable diseases; PEFR, peak expiratory flow rate; $\mathrm{RCTs}$, randomized controlled trials; UMICs, upper middle income countries

\section{Authors' contributions}

VS conceived the idea, collected data, participated in analysis and drafting of manuscript. WQ participated in analysis and drafting of manuscript. DO collected data, participated in analysis and drafting of manuscript. All authors read and approved the final manuscript.

\section{Availability of data and materials}

The datasets supporting the conclusions of this article are included within the article and its Additional files 1 and 2 .

\section{Competing interests}

The authors declare that they have no competing interests.

Consent for publication

Not applicable 


\section{Ethics approval and consent to participate}

Not applicable

\section{Received: 5 February 2016 Accepted: 28 June 2016 Published online: 15 July 2016}

\section{References}

1. Weiser TG, Regenbogen SE, Thompson KD, Haynes AB, Lipsitz SR, Berry WR, et al. An estimation of the global volume of surgery: a modelling strategy based on available data. Lancet. 2008;372(9633):139-44

2. Alwan A. Global status report on noncommunicable diseases 2010. Geneva: World Health Organization; 2011.

3. Bloom DE, Cafiero E, Jané-Llopis E, Abrahams-Gessel S, Bloom LR, Fathima S, et al. The global economic burden of noncommunicable diseases. Program on the Global Demography of Aging. 2012.

4. HME. Global Burden of Diseases: Compare 2013. Database: GBD Compare [Database]. Available: http://vizhub.healthdata.org/gbd-compare. Accessed 11 Jul 2016.

5. Boutayeb A. The double burden of communicable and non-communicable diseases in developing countries. Trans R Soc Trop Med Hyg. 2006;100(3):191-9.

6. WHO. World health statistics 2010. World Health Organization; 2010. Available: http://www.who.int/whosis/whostat/2010/en/. Accessed 11 Jul 2016.

7. ITU. World Telecommunication/ICT Development Report 2010 - Monitoring the WSIS targets2010. Available: http://www.itu.int/pub/D-IND-WTDR-2010/en. Accessed 11 Jul 2016.

8. Kaplan WA. Can the ubiquitous power of mobile phones be used to improve health outcomes in developing countries. Glob Health. 2006;2(9):1-14.

9. Worldbank. Data-indicators2014 [Database]. Available:http://data.worldbank. org/indicator. Accessed 11 Jul 2016.

10. ITU. World telecommunication/ICT indicators database 2013; 2013. Available: http:/www.itu.int/en/TU-D/Statistics/Documents/facts/ICTFactsFigures2013-e.pdf. Accessed 11 Jul 2016.

11. Kay M, Santos J, Takane M. mHealth: New horizons for health through mobile technologies. World Health Organization. 2011:66-71. Available: http://apps.who.int/iris/bitstream/10665/44607/1/9789241564250_eng.pdf. Accessed 11 Jul 2016.

12. Kahn JG, Yang JS, Kahn JS. 'Mobile'health needs and opportunities in developing countries. Health Aff. 2010;29(2):252-8.

13. Mbuagbaw L, Mursleen S, Lytvyn L, Smieja M, Dolovich L, Thabane L. Mobile phone text messaging interventions for HIV and other chronic diseases: an overview of systematic reviews and framework for evidence transfer. BMC Health Serv Res. 2015;15(1):33.

14. Hall CS, Fottrell E, Wilkinson S, Byass P. Assessing the impact of mHealth interventions in low- and middle-income countries - what has been shown to work? Glob Health Action. 2014;7:25606. doi:10.3402/gha.v7.25606.

15. Beratarrechea A, Lee AG, Willner JM, Jahangir E, Ciapponi A, Rubinstein A. The impact of mobile health interventions on chronic disease outcomes in developing countries: a systematic review. Telemed E Health. 2014;20(1):75-82.

16. Bloomfield GS, Vedanthan R, Vasudevan L, Kithei A, Were M, Velazquez EJ. Mobile health for non-communicable diseases in Sub-Saharan Africa: a systematic review of the literature and strategic framework for research. Glob Health. 2014;10(1):49.

17. Barton S. Which clinical studies provide the best evidence?: The best RCT still trumps the best observational study. BMJ. 2000;321(7256):255.

18. Matthews JN. Introduction to randomized controlled clinical trials. 1st ed. Boca Raton: CRC Press; 2006.

19. World Bank W. Country and Lending Groups 2015. [Database]. Available: http:// data.worldbank.org/about/country-and-lending-groups. Accessed 11 Jul 2016.

20. WHO. Noncommunicable diseases 2015. [Database]. Available: http://www. who.int/nmh/databases/en/. Accessed 11 Jul 2016.

21. Howitt P, Darzi A, Yang G-Z, Ashrafian H, Atun R, Barlow J, et al. Technologies for global health. Lancet. 2012;380(9840):507-35.

22. Reeves BC, Deeks JJ, Higgins JP. 13 Including non-randomized studies. Cochrane Handb Syst Rev Interv. 2008;1:391.

23. Piette JD, Datwani H, Gaudioso S, Foster SM, Westphal J, Perry W, et al. Hypertension management using mobile technology and home blood pressure monitoring: results of a randomized trial in two low/middle-income countries. Telemed E Health. 2012;18(8):613-20.

24. Tian M, Ajay V, Dunzhu D, Hameed S, Li X, Liu Z, et al. A cluster-randomized controlled trial of a simplified multifaceted management program for individuals at high cardiovascular risk (SimCard Trial) in Rural Tibet, China, and Haryana, India. Circulation. 2015:132(9):815-24.

25. Balsa Al, Gandelman N. The impact of ICT on health promotion: A randomized experiment with diabetic patients. IDB Working Paper No 76; 2010. Available: http://idbdocs.iadb.org/wsdocs/getdocument. aspx?docnum=35552241. Accessed $11 \mathrm{Jul} 2016$.

26. Shetty AS, Chamukuttan S, Nanditha A, Raj R, Ramachandran A. Reinforcement of adherence to prescription recommendations in Asian Indian diabetes patients using short message service (SMS)-a pilot study. J Assoc Physicians India. 2011;59:711-4.

27. Shahid M, Mahar SA, Shaikh S, Shaikh Z. Mobile phone intervention to improve diabetes care in rural areas of pakistan: a randomized controlled trial. J College of Physicians Surg Pak. 2015;25(3):166-71.

28. Liu W-T, Huang C-D, Wang C-H, Lee K-Y, Lin S-M, Kuo H-P. A mobile telephone-based interactive self-care system improves asthma control. Eur Respir J. 2011:37(2):310-7.

29. Ostojic V, Cvoriscec B, Ostojic SB, Reznikoff D, Stipic-Markovic A, Tudjman Z. Improving asthma control through telemedicine: a study of short-message service. Telemed J E Health. 2005;11(1):28-35.

30. Liew S-M, Tong SF, Lee VKM, Ng CJ, Leong KC, Teng CL. Text messaging reminders to reduce non-attendance in chronic disease follow-up: a clinical trial. Br J Gen Pract. 2009:59(569):916-20.

31. Gurman TA, Rubin SE, Roess AA. Effectiveness of mHealth behavior change communication interventions in developing countries: a systematic review of the literature. J Health Commun. 2012;17(sup1):82-104.

32. Velthoven M, Brusamento S, Majeed A, Car J. Scope and effectiveness of mobile phone messaging for HIV/AIDS care: a systematic review. Psychol Health Med. 2013;18(2):182-202.

33. Déglise C, Suggs LS, Odermatt P. SMS for disease control in developing countries: a systematic review of mobile health applications. J Telemed Telecare. 2012;18(5):273-81.

34. Lau YK, Cassidy T, Hacking D, Brittain K, Haricharan HJ, Heap M. Antenatal health promotion via short message service at a Midwife Obstetrics Unit in South Africa: a mixed methods study. BMC Pregnancy Childbirth. 2014;14(1):284.

35. Fedha T. Impact of mobile telephone on maternal health service care: a case of Njoro division. Open J Prev Med. 2014;4(No.5):2014.

36. Lund S, Hemed M, Nielsen BB, Said A, Said K, Makungu M, Rasch V. Mobile phones as a health communication tool to improve skilled attendance at delivery in Zanzibar: a cluster-randomised controlled trial. BJOG. 2012;119(10):1256-64.

37. Thirumurthy H, Lester RT. M-health for health behaviour change in resource-limited settings: applications to HIV care and beyond. Bull World Health Organ. 2012;90(5):390-2

38. Pop-Eleches C, Thirumurthy H, Habyarimana JP, Zivin JG, Goldstein MP, De Walque D, Mackeen L, Haberer J, Kimaiyo S, Sidle J. Mobile phone technologies improve adherence to antiretroviral treatment in a resourcelimited setting: a randomized controlled trial of text message reminders. AIDS (London, England). 2011;25(6):825

39. Zurovac D, Larson BA, Sudoi RK, Snow RW. Costs and cost-effectiveness of a mobile phone text-message reminder programmes to improve health workers adherence to malaria quidelines in Kenya. PLoS One. 2012;7(12):e52045.

40. Fruhauf J, Hofman-Wellenhof R, Kovarik C, Mulyowa G, Alitwala C, Soyer HP, Kaddu S. Mobile teledermatology in sub-Saharan Africa: a useful tool in supporting health workers in low-resource centres. Acta Derm Venereol. 2013;93(1):122-3.

41. Quinley KE, Gormley RH, Ratcliffe SJ, Shih T, Szep Z, Steiner A, Ramogola-Masire D, Kovarik CL. Use of mobile telemedicine for cervical cancer screening. J Telemed Telecare. 2011:17(4):203-9.

42. Tran K, Ayad M, Weinberg J, Cherng A, Chowdhury M, Monir S, El Hariri M, Kovarik C. Mobile teledermatology in the developing world: implications of a feasibility study on 30 Egyptian patients with common skin diseases. J Am Acad Dermatol. 2011:64(2):302-9.

43. Desai S, Patil R, Chinoy R, Kothari A, Ghosh T, Chavan M, Mohan A, Nene B, Dinshaw K. Experience with telepathology at a tertiary cancer centre and a rural cancer hospital. Natl Med J India. 2004;17(1):17.

44. Stephani V, Opoku D, Quentin W. Does mHealth contribute to improved care for people with non-communicable diseases in developing countries? Working papers in health policy and management. 2015. p. 10. 